\title{
Measurement of luminescent banding in speleothems: some techniques and limitations
}

\author{
Bryan E. Crowell ${ }^{1}$ and William B. White ${ }^{2}$
}

\begin{abstract}
:
Crowell B.E. and White W.B. 2012. Measurement of luminescent banding in speleothems: Some techniques and limitations. International Journal of Speleology, 41(1), 51-58. Tampa, FL (USA). ISSN 0392-6672. http://dx.doi.org/10.5038/1827-806X.41.1.6

Speleothems, especially flowstone and cylindrical stalagmites, exhibit phosphorescence which is often banded on the scale of a few tens of micrometers. The luminescence bands are paleoclimatic records with a very high temporal resolution. A technique has been developed using a laser source and a high resolution Raman spectrometer with microscope and computer-controlled translation stage for both luminescence profiles and luminescence spectroscopy. Luminescence intensity could be measured as a function of traverse distance with a spatial resolution of $2-3 \mu \mathrm{m}$. Potential sources of error include loss of intensity due to radiation damage by the laser beam, irregularities, cracks, and inclusions on the polished speleothem surface, and defocusing of the beam along the traverse path.
\end{abstract}

Keywords: speleothems; luminescence banding; spectroscopy; lasers

Received 13 April 2011; Revised 28 June 2011; Accepted 29 June 2011

\section{INTRODUCTION}

For the past several decades speleothems have been recognized as useful repositories of paleoclimatic data. Growth rates of speleothems are highly variable but generally fall into the range of fractions of a micrometer to hundreds of micrometers per year. In general, flowstone exhibits the slowest growth rates compared with stalagmites. Speleothem growth starts, stops, and changes rate depending on climatic conditions on the overlying land surface, on changing vegetative cover, on storage and flow in the epikarst and on flow paths through the vadose zone between the epikarst and the cave. By using U/Th dating to establish time scales, speleothems have provided a microstratigraphy of mineral textures, trace element profiles, and isotope profiles that extend well back into the Pleistocene. A large literature has appeared as suggested by the reviews of Perrette (1999), McDermott (2004), White (2004), Fairchild et al. (2006), Baker et al. (2008)

One of the more enigmatic of the speleothem records is the luminescence banding. It has long been known that most speleothems are phosphorescent, emitting a bluish to greenish white luminescence

${ }^{1}$ Meiser \& Earl, Inc., 1512 West College Avenue, State College, PA 16801, USA. (bcrowell@meiser-earl.com)

${ }^{2}$ Materials Research Institute, Materials Research Laboratory Bldg., The Pennsylvania State University, University Park, PA 16802, USA. (wbw2@psu.edu) when excited by a photographer's strobe lamp or by an ultraviolet lamp. The luminescence arises from organic molecules, mainly fulvic and humic acids, incorporated into the calcite of the speleothem during growth (Lauritzen et al., 1986; White \& Brennan, 1989; van Beynen et al., 2001). About 1985, Yavor Shopov (Shopov \& Grynberg, 1985; Shopov, 1987) discovered that the luminescence of many speleothems appears as alternating bands of bright and less bright luminescence. The bands are perpendicular to the growth axis of the speleothem and are spaced from fractions to hundred of micrometers apart. It was very quickly demonstrated that the luminescence bands are annual growth bands and that the luminescence banding records, therefore, have a temporal resolution of at least one year, maybe less (Shopov et al., 1988; Baker et al, 1993; Shopov et al., 1994). Features in the banding profiles have been correlated with climatic and other phenomena, such as the proposed record of the Hekla 3 eruption of 1135 BCE (Baker et al., 1995). Many investigations of luminescence banding have been published or are underway (Perrette, 1999; Baker et al., 2008).

In spite of all of these investigations, relatively little attention has been paid to the methodology of measuring luminescence banding and the consistency and reproducibility of the results. The original discovery was made by photographing the bands and using a densitometer to measure the darkening of the photographic film. Others have used UV laser sources combined with spectrometers or have used digital cameras to record the banding. More recently 
a luminescence spectrometer with fiber-optic probe has been used (Baker \& Bolton, 2000; Sundqvist et al., 2005; Asrat et al., 2007).

It is useful to be able to record luminescence intensity with high precision and also to measure luminescence spectra on the scale of the individual bands. The microfocus Raman spectrometer is a useful device for measurement of luminescence banding because of the laser excitation and because of the high spatial resolution (White, 1997). The objective of the present paper paper is to present some of the values and limitations of this particular approach to the measurement of luminescent banding in speleothems.

\section{SAMPLES, SPECTROSCOPIC EQUIPMENT AND MEASUREMENTS}

\section{Speleothems for measurement}

A selection of speleothems from various caves and climatic regimes were used as test specimens. Because the objective was only to evaluate measurement techniques, what was needed was a range of speleothem textures and banding patterns rather than specimens linked to specific localities or specific climatic regimes. Speleothems are identified by sample numbers that refer to a reference collection of cave material maintained by the corresponding author (Table 1).

Table 1. Sources of specimens chosen for examination

\begin{tabular}{lll}
\hline Sample Number & Description & \multicolumn{1}{c}{ Source } \\
\hline 155 & Dark brown stalactite & Lawrence Domepit Cave, WV \\
416 & Stalactite & Turner Ave., Mammoth Cave, KY \\
689 & Tan stalagmite & Prah Cave, PA \\
691 & Orange-brown stalactite & Prah Cave, PA \\
1067 & Tan stalagmite & Coffee River Cave, Jamaica \\
88 MM004 & Orange-brown stalagmite & J-4 Cave, Centre County, PA \\
83 MM005 & Travertine crevice filling & Rilda Canyon, Utah \\
DBO & Tan stalagmite & Cueva del Diablo, Chihuahua, Mexico \\
USSM\#2-1a & Recent stalagmite & U.S. Steel Mine \#2, Lawrence Co., PA \\
WWC-1, 2, 3 & Flowstone, <75 years & Woodward Cave, Centre Co., PA
\end{tabular}

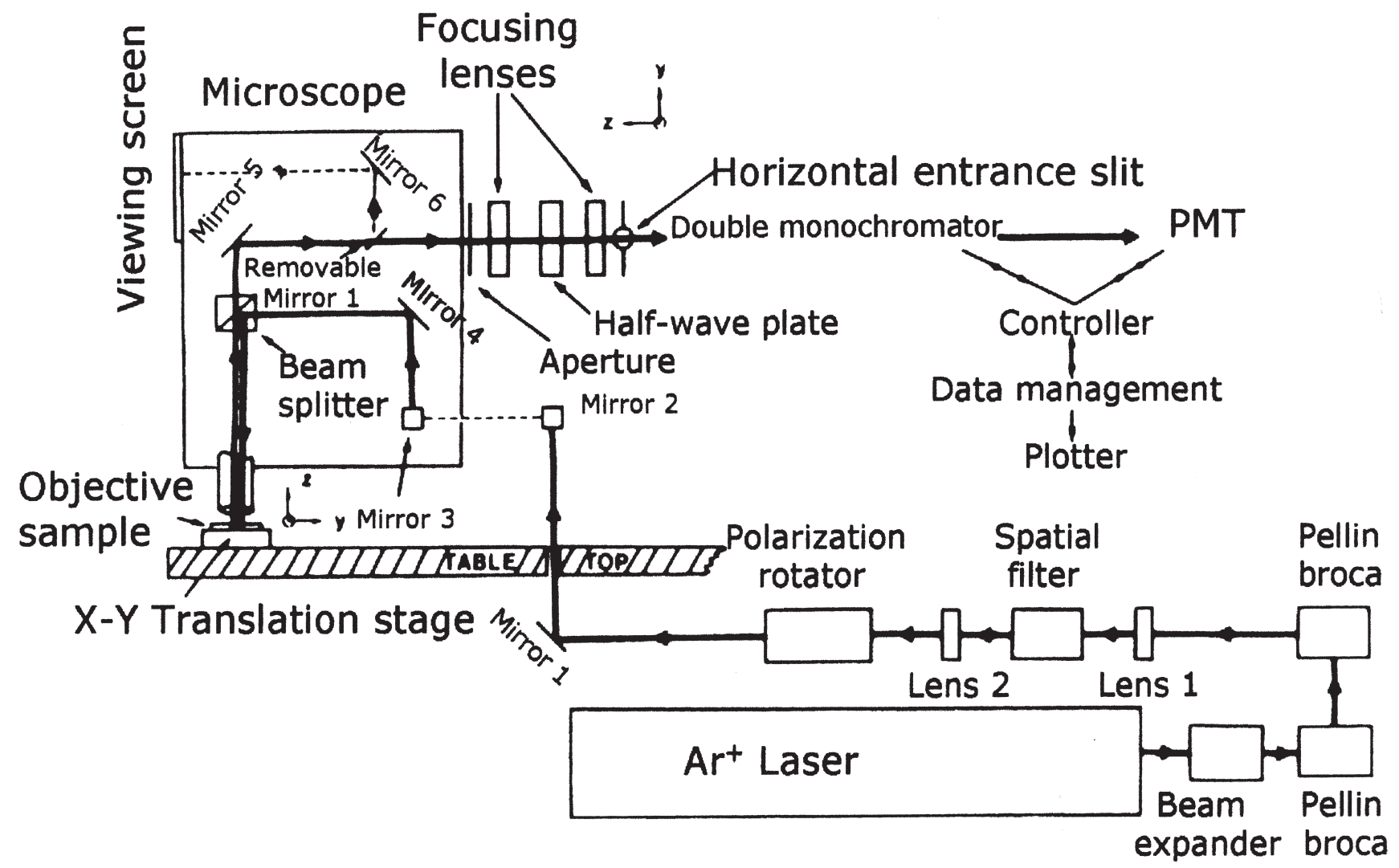

Fig. 1. Diagram showing the optical path and key components of the Raman spectrometer. 


\section{The microfocus spectrometer}

The base instrument was an Instruments SA Ramanor U-1000 microfocus Raman spectrometer (Fig. 1). The excitation source was an argon ion laser which provided blue $(488 \mathrm{~nm})$ or green $(514.5$ $\mathrm{nm})$ beams. The laser beam is guided through some steering optics into a beam splitter within the microscope. The incoming beam is attenuated by about a factor of 10 by the beam splitter. From the beam splitter, the laser beam passes through the microscope objective and is brought to a focus on the sample mounted on the microscope stage. The size of the focal spot is diffraction limited but as a practical matter is $1-2 \mu \mathrm{m}$. For the present experiments, the power level of the laser was set at $50 \mathrm{~mW}$. The actual power at the focal spot is difficult to determine but, allowing for losses along the optical train, would be in the range of $4-5 \mathrm{~mW}$.

Radiation emitted by the sample, either Raman scattering (the normal use of the instrument) or luminescence, is collected by the objective lens of the microscope and transmitted back to the beam splitter which in the reverse direction transmits $90 \%$ of the radiation to the entrance slit of a 1 -meter focal length, high resolution double monochromator. The signal is detected by a cooled photomultipler, and passes through some interface electronics to the computer. The computer software allows data storage, manipulation, and display. The instrument displays spectra as plots of intensity (count rate) vs. wavenumber rather than the wavelength scale commonly used in luminescence measurements.

\section{Translation stage}

For the luminescence banding experiments, the microscope stage was replaced with an Aerotech ATS15020 linear translation stage coupled with a BAI 10-160 driver and a BMS 60 motor. This system has a step interval of $1.25 \mu \mathrm{m}$, an accuracy of $2.0 \mu \mathrm{m}$ per $25 \mathrm{~mm}$ of travel, and a bi-directional repeatability of $2.0 \mathrm{\mu m}$. The stage was controlled by software run on the same computer that controlled the Raman system. Programs were written to move the stage and sample predetermined distances at specified rates for data collection along the traverse path. A dwell time of 1.5 seconds was used to obtain the count rate at each point of measurement. A further addition to the automated stage was the mounting of a manual translation stage perpendicular to the travel direction of the automated stage. This permitted the construction of a sequence of parallel traverses along the same specimen.

\section{Instrumental errors}

Published paleoclimatic records are notoriously noisy and it is frequently difficult to separate the actual climatic signal from the background fluctuations. One must also distinguish between noisy equipment and noisy data. The measurement apparatus will have a certain intrinsic random error (noise) that must be evaluated. However, measurements on natural systems, such as speleothems, will have a measurement-to-measurement variability that would be present even if the measurements were ideally accurate. This is what is meant by "noisy data".

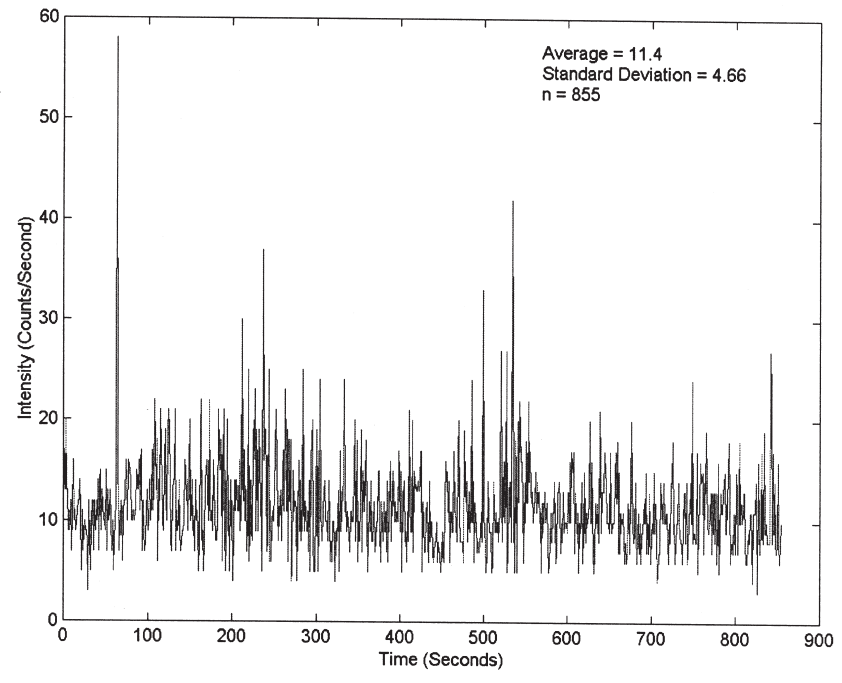

Fig. 2. Photomultiplier background noise.

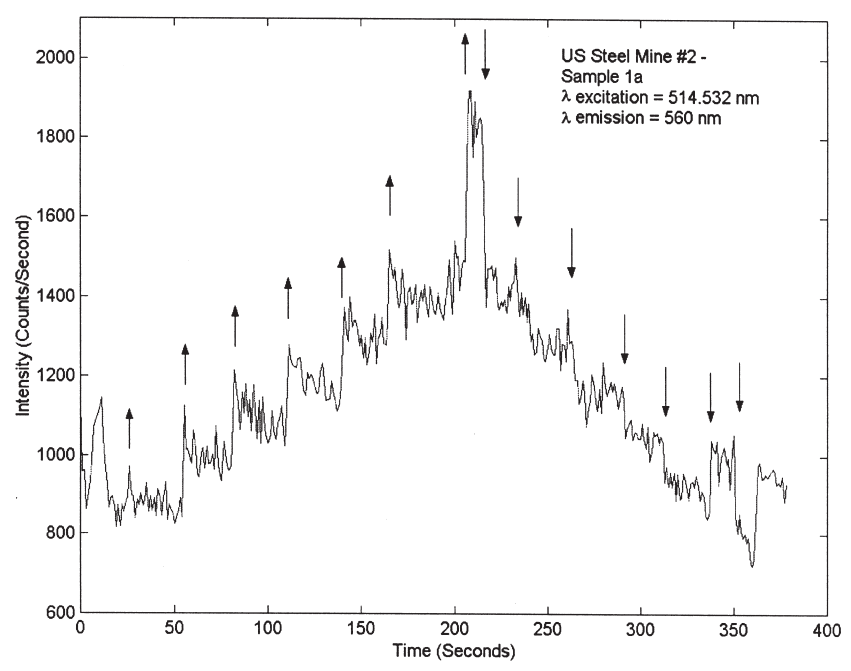

Fig. 3. Focusing errors. The arrows show direction of an induced $18 \mu \mathrm{m}$ defocus. Data acquisition began with the sample in focus.

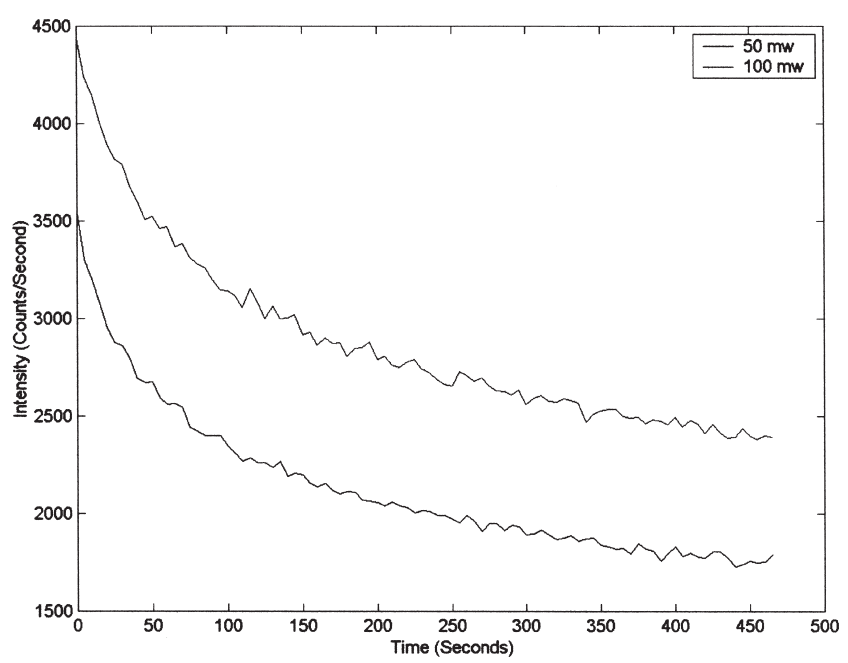

Fig. 4. Degradation of speleothem luminescence under $514.5 \mathrm{~nm}$ laser radiation at two power levels. Luminescence measured at $565 \mathrm{~nm}$. 


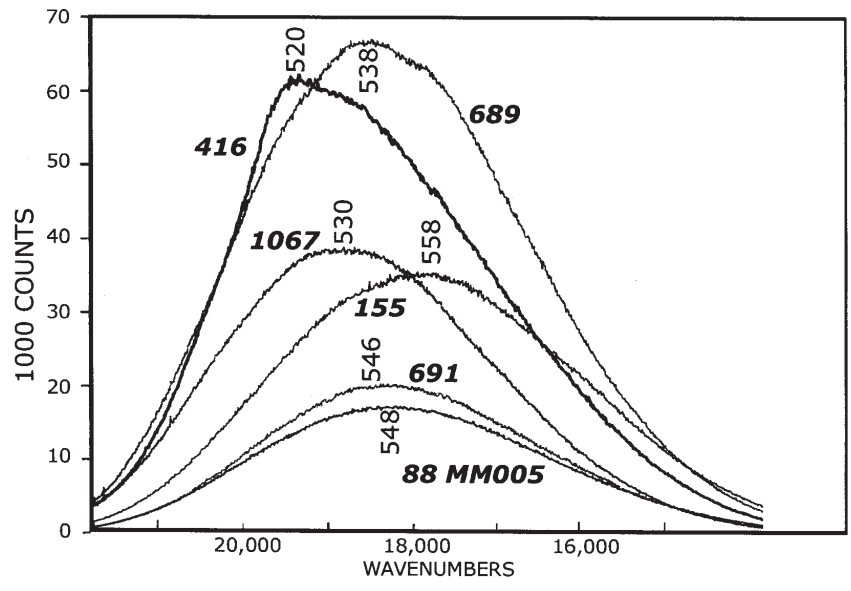

Fig. 5. Emission spectra from six speleothems under $457.9 \mathrm{~nm}$ excitation. The spectrometer used displays results as wavenumber plots; peak wavelengths are shown for each spectrum. Numbers in boldface are sample numbers (see Table 1).

The photomultiplier detector counts individual photons so the count rate is the basic unit of intensity. Photomultiplier noise was determined by carefully sealing off any extrinsic sources of light including darkening the laboratory and allowing the tube to count in complete darkness for 1100 seconds (Fig. 2). The random noise from this source was 7.67 counts / second with a standard deviation of 2.88 counts/ second. In spite of all precautions, a minute amount of light can enter the spectrometer from ambient room lighting. Running the spectrometer with normal ambient lighting (daylight and/or room lighting) raised the dark signal to 8.55 counts/ second. Scattered light from the laser is a third source of background noise so that the signal from the fully operational spectrometer has a total background randomness of 11.4 counts / second with a standard deviation of 4.66. All spectra will have this level of uncertainty. The significance of the background noise will depend on the signal strength of the particular spectrum being measured.

A variable of critical importance either in sample-to-sample or sampling site-to-sampling site measurements is the accuracy of focus. The advantage of using a microscope to make measurements is the

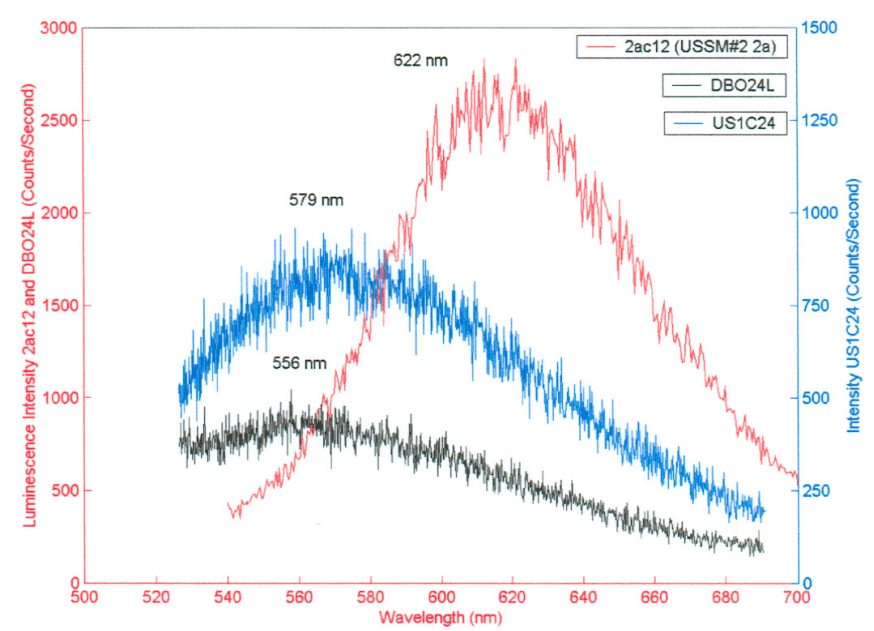

Fig. 6. Emission spectra for three speleothems excited by the $514.5 \mathrm{~nm}$ laser line. very high spatial resolution. An ancillary problem is that the focus must remain sharp even when the sample is being moved along a translation stage. The objective lens of the microscope is designed to gather light from the excited area of a sample. If the lens is poorly focused, a larger area is illuminated, and light is gathered from a correspondingly larger sample area. The sensitivity of the system to focus was tested by defocusing the microscope in abrupt $18 \mu \mathrm{m}$ intervals (Fig. 3). A single $18 \mu \mathrm{m}$ defocus can impact the luminescence intensity by 5 to $15 \%$. Gradual defocusing over time or along the traverse distance can create artifacts such as artificial trends in the data.

\section{Laser damage}

The luminescent entities in speleothems are complex organic molecules and, as such, may be subject to damage, either from the laser sources used in the present experiments, or from the ultraviolet radiation used in other investigations. By simply measuring the luminescence intensity from a single spot on a sample as a function of time, the continuing impact of the radiation can be determined (Fig. 4). The decay curve is exponential and over the 8-minute duration of the experiment, about $50 \%$ of the intensity was lost. Using different power levels in the laser shifts the initial intensity but the shape of the decay curve remains the same. There is no threshold; loss of intensity begins immediately on exposure of the sample to the laser. A spectrum scanned from a single spot will suffer some intensity loss between the beginning of the scan and the end, possibly distorting the spectral line shape. The measurement of intensity at a fixed wavelength along a continuous traverse is less likely to be distorted because the exposure at each point of the traverse will be the same.

\section{LUMINESCENCE SPECTROSCOPY}

\section{Laser excited spectra}

Excitation of a selection of speleothems with the $457.9 \mathrm{~nm}$ line of an argon ion laser produced the results shown in Figure 5. A second set of specimens was excited by the $514 \mathrm{~nm}$ argon ion laser line (Fig. 6). In both sample sets, the emission appears as a broad band with peak wavelength that varies somewhat from specimen to specimen. However, the most dramatic feature is that the emission bands have shifted far out into the visible spectrum from where they appear under UV excitation. One specimen exhibits a red luminescence under $514 \mathrm{~nm}$ excitation. Speleothems contain mixtures of humic and fulvic acids and the longer wavelength excitation activates the higher molecular weight fraction which have longer emission wavelengths. In effect, the laser-source spectrometer is probing a different set of organic molecules than is probed by the usual UV sources.

With the microfocus spectrometer it is possible to measure spectra of individual bands within a slice of speleothem (Fig. 7). The band shapes and band positions are very similar to bands measured by averaging across multiple bands as is done without the microscope. The results of several comparisons 
show that the band-to-band spectra are very similar suggesting that it is the relative concentrations of luminescing molecules that vary from band to band, rather than a different mix of molecular species.

\section{MEASUREMENT OF LUMINESCENCE BANDING}

\section{Traverse measurement and reproducibility}

Samples were placed on the translation stage with the growth bands oriented perpendicular to the translation direction. The samples were then leveled across the entire translation distance to maintain maximum accuracy in luminescence measurements. To insure that the sample was level, the focus was checked at both ends of the traverse and at several points in the middle. It was possible to maintain laser focus on the sample for the entire length of the traverse.

The reproducibility of individual traverses were measured by doing one traverse, then backing off the stage and doing the same traverse a second time. Visual inspection of a typical result (Fig. 8) suggests that the agreement is good but not perfect. To obtain a more quantitative assessment, a point-by-point comparison was made and the goodness of fit, $\mathrm{R}^{2}$, was calculated for the entire sequence of points. The correlation of the traverses shown in Figure 8 gives an $R^{2}$ value of 0.84 , suggesting that visual evaluation may be somewhat optimistic.

\section{Reproducibility of parallel traverses on the same specimen}

The distribution of organic luminophores in the calcite matrix of a speleothem is a relatively unstudied topic. Bands are known to be present in many samples, but the fine scale structure of the bands is unknown. Several parallel traverse studies were undertaken to achieve a better understanding of the luminescent structure of speleothems. The correlation coefficient again proved to be useful in comparing the traverses with each other. Figure 9 shows the results of two parallel traverses that were horizontally offset by $30 \mu \mathrm{m}$ using the manual translation stage mounted perpendicular to the automated stage. Visual inspection of the two traverses suggests a good match but the value of $\mathrm{R}^{2}$ is only 0.76 . More careful inspection of the two traverses reveals that although the overall patterns are very similar, they are, in fact, slightly offset from each other. By shifting one traverse slightly with respect to the other, it is possible to achieve a value of $\mathrm{R}^{2}$ of 0.94 . The bands are not precisely perpendicular to the growth axis so that the offset is needed to bring them into alignment.

Continued good correlations were obtained by a comparison of five traverses spaced $50 \mu \mathrm{m}$ apart. After adjusting for small off-sets, $\mathrm{R}^{2}$ values for the traverse-to-traverse comparisons ranged from 0.91 to 0.95. It appears that reproducible results can be obtained for luminescence traverses along the growth axis of a single speleothem so long as the traverses are close together. When luminescence profiles are measured at wide spacings, the reproducibility of the record tends to be lost (Fig. 10).

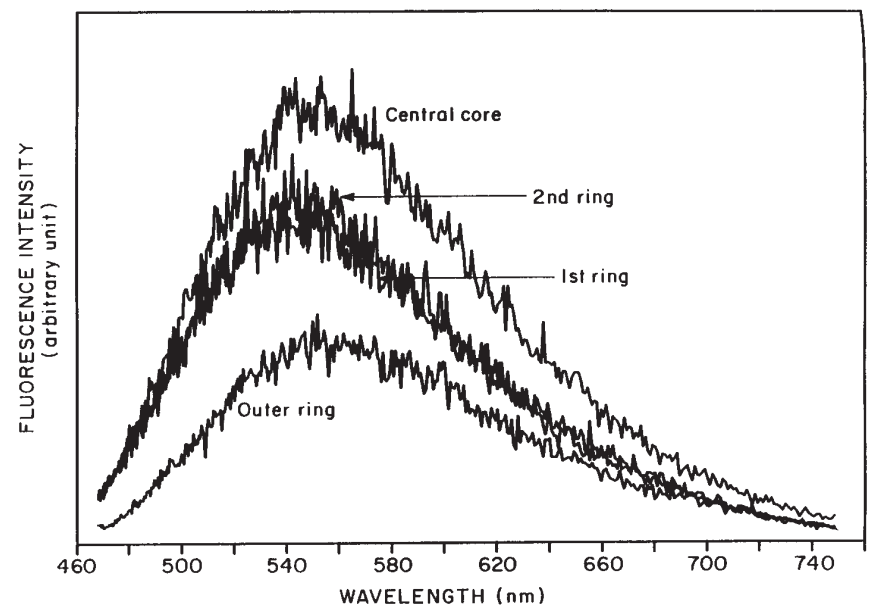

Fig. 7. Emission spectra from exciting four alternating colored regions of specimen $88 \mathrm{MM} 004$ by the 457.9 laser line.

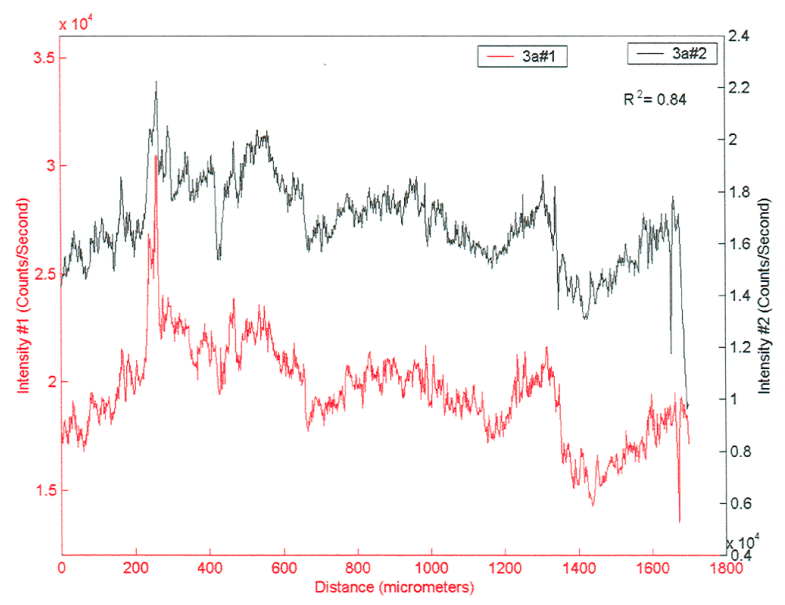

Fig. 8. Duplicate traverses across flowstone WWC-Flow-3a. Intensities were collected at intervals of $1.67 \mu \mathrm{m}$.

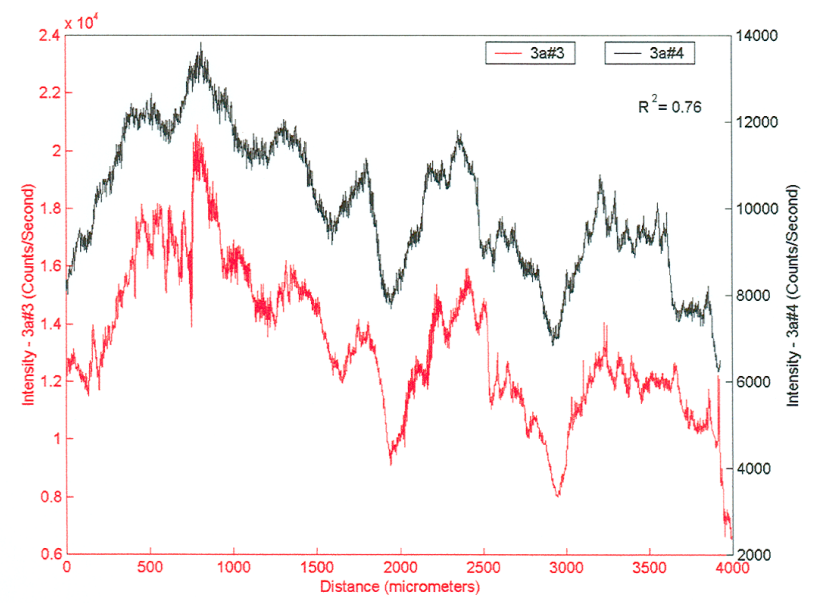

Fig. 9. Parallel traverses across specimen WWC-Flow-3a. The spacing of individual points is $1.67 \mu \mathrm{m}$. 


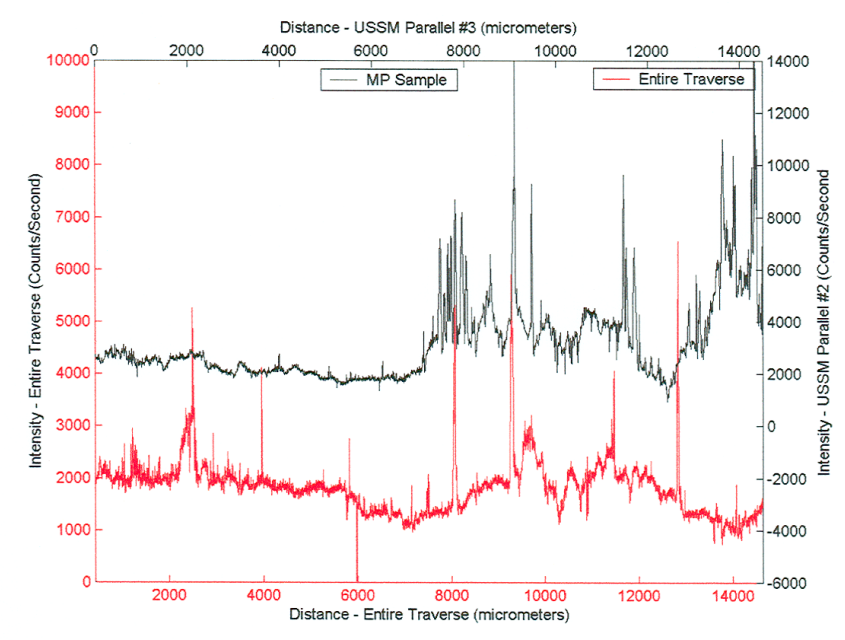

Fig. 10. Luminescence traverses across specimen USSM\#2-Mite1a. The horizontal offset between the traverses was roughly 5 $\mathrm{mm}$. Note the spikes arising from surface flaws in the polished specimen.

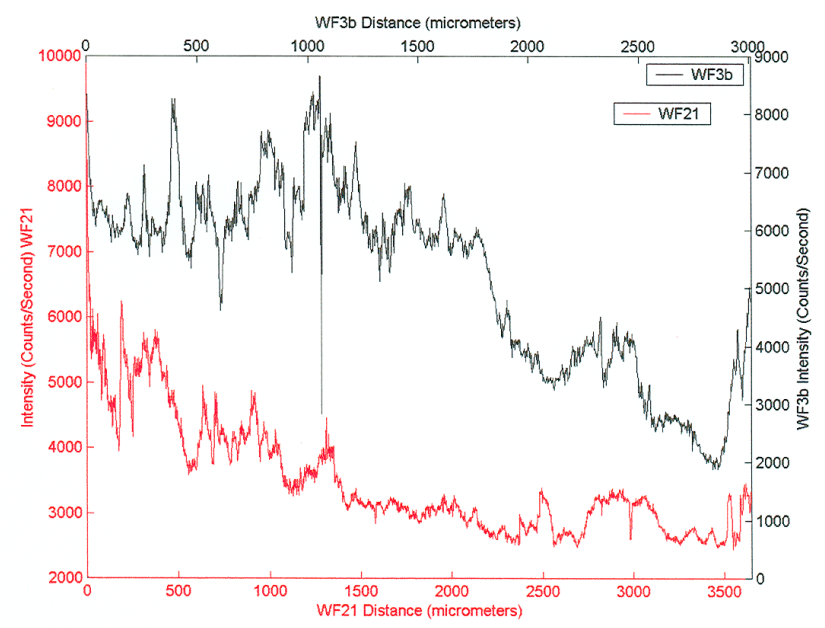

Fig. 11. Luminescence traverses of WWC-Flow-2 and WWCFlow-3b from Woodward Cave. The samples were collected from flowstone deposits spaced approximately 50 meters apart.

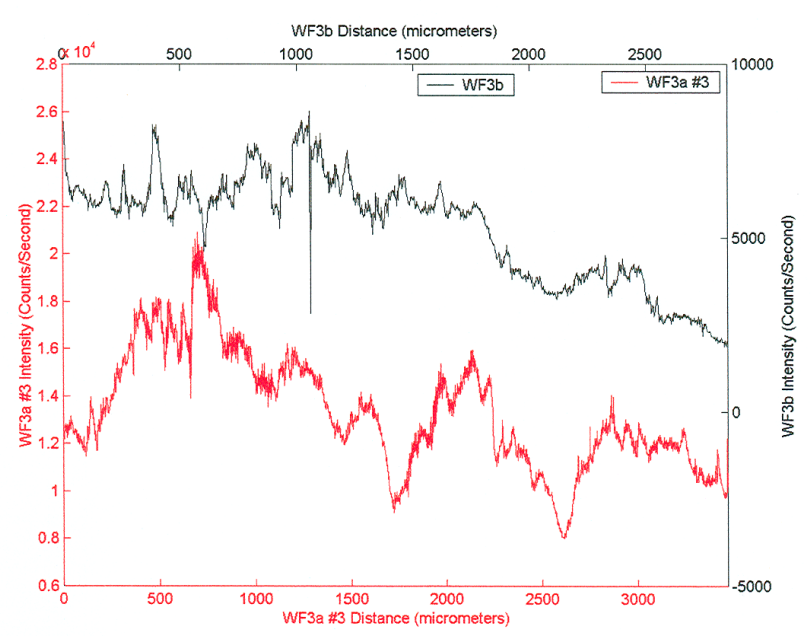

Fig. 12. Luminescence traverses of WWC-Flow-3a and WWCFlow-3b from Woodward Cave. The samples were collected less than one centimeter apart and located on the same flowstone line.
Although correlation values are high for the entire traverse, fine scale differences appear to be uncorrelated. Expanding the scale and examining point-by-point correlations over short traverse distances brought $\mathrm{R}^{2}$ down to 0.64. Further comparison of five scans confirms the lack of fine scale correlation. The very fine-scale variations seen in all of the traverse plots are indeed exactly what they appear to be - noise.

\section{Effect of surface flaws and irregularities}

A downside to automated electronic scans compared to the photographic methods used in early work is the effect of surface flaws on the record. The photographic record is two-dimensional and any irregularity in the image of a band can be ignored. The electronic scans are one-dimensional. When a flaw such as a grain boundary or an inclusion passes under the sharply-focused laser beam, a sharp spike appears in the record. These spikes are very sharp and are easily recognized in a visual inspection of a traverse plot, but they have the potential for creating artifacts in electronic processing of the raw data.

\section{Specimen to specimen reproducibility}

Most caves contain large numbers of speleothems but conservation ethics demand that sampling be conservative and that as few speleothems as possible be removed from the caves. All of the paleoclimate records in speleothems, including age-dating profiles, isotope profiles, trace element profiles, and color and luminescent banding profiles, are intrinsically destructive in that the specimens must be removed from the cave and sliced and polished. This leads to questions of how to select the specimens for measurement and the extent to which this selection affects the outcome of the investigation.

Some insight into the question of specimen-tospecimen reproducibility is provided by the samples from Woodward Cave, Pennsylvania (the WWC series in Table 1). The flowstone samples from Woodward Cave grew between the time when the largely mudand silt-filled stream passage was excavated for commercial development in 1924 and time of sample collection in 2000. All of the Woodward Cave samples are approximately the same age and all have the same surface climatic history. What differs between them are the details of the epikarst through which the rainfall passed, and the exact route followed by the vadose water on its path from the epikarst to the growing speleothem.

Traverses of two specimens with a separation of approximately 50 meters are shown in Figure 11 . The large down-spike shown in traverse WF3b at 1060 $\mu \mathrm{m}$ is a single data point anomaly with no discernible surface irregularity related to it. The intensity decrease in the WF2 1 traverse at $2982 \mu \mathrm{m}$ distance is a well-defined feature $17 \mu \mathrm{m}$ wide with ten data points collected in it. There is no recognizable surface irregularity associated with this intensity decrease. There is some agreement in these two traverses if allowance is made for a small offset.

In contrast, the traverses shown in Figure 12 are from specimens located side-by-side on the same line 
of flowstone in the cave. The total distance between the samples was less than one centimeter. There is little or no matching between the two intensity plots. Although the speleothems grew in close proximity in the cave, it is apparent that the flow path connecting precipitation on the land surface to the growing speleothem must have been quite different.

\section{CONCLUSIONS}

Careful analysis of sources of error in the measurement of luminescent banding in speleothems shows that reliable intensity vs. traverse distances at high spatial resolution can be obtained from equipment intended for other types of spectroscopy. Instrumental sources of error are small and can be controlled. Comparisons of accurate intensity profiles, however, do reveal important sources of variability intrinsic to the speleothems. Luminescence profiles obtained along parallel tracks in the same speleothem are quite reproducible. Luminescence profiles on different speleothems that grew over the same time period, unfortunately, are very poorly correlated. Profiles obtained on a single speleothem represent only a single pathway through the epikarst and the vadose zone. Generalizations from such measurements should be made with great caution.

The photometric measurements described in this paper are offered as an alternative to the established photographic methods, not a replacement for them. The spatial resolution of 1-2 $\mu \mathrm{m}$ may be limiting for the slowest growing speleothems with band spacings of fractions of a micrometer. However, for banding in the 10-100 $\mu \mathrm{m}$ range offers a direct measurement of band structure in considerable de tail.

The comparisons made in this paper are over relatively short traverse distances, typically one to two centimeters. The results, therefore, are indicative of the variations and sources of error over time periods of at most a few centuries. They do not address problems that might occur over the much longer time spans of speleothem paleoclimate investigations. Although the comparisons reported here were done with a specific apparatus, the sources of variation identified would apply to comparable measurements made with any other apparatus. The details might be different, but the sources of extraneous signal variability that would need to be checked would be the same.

\section{ACKNOWLEDGEMENTS}

This work was supported by the U.S. National Science Foundation under grant No. EAR 9809138. We thank Mr. Peter Burd of Woodward Cave for permission to collect the Woodward Cave specimens.

\section{REFERENCES}

Asrat A., Baker A., Umer Mohammed M., Leng M.J., van Calstern P., \& Smith C., 2007 A high-resolution multi-proxy stalagmite record from Mechara, Southeastern Ethiopia: Palaeohydrological implications for speleothem palaeoclimate reconstruction. Journal of Quaternary Science, 22: 53-63. http://dx.doi.org/10.1002/jqs.1013
Baker A., Smart P.L., Edwards R.L. \& Richards D.A., 1993 - Annual growth banding in a cave stalagmite. Nature, 364: 518-520. http://dx.doi.org/10.1038/364518a0

Baker A., Smart P.L., Barnes W.L., Edwards R.L. \& Farrant A., 1995 - The Hekla 3 volcanic eruption recorded in a Scottish speleothem. The Holocene, 5: 336-342.

http://dx.doi.org/10.1177/095968369500500309

Baker A., \& Bolton L., 2000 - Speleothem organic acid luminescence intensity ratios: a new palaeoenvironmental proxy. Cave and Karst Science, 27: 121-124.

Baker A., Smith C.L., Jex C., Fairchild I.J., Genty D. \& Fuller L., 2008 - Annually laminated speleothems: a review. International Journal of Speleology, 37: 193-206.

Fairchild I.J., Smith C.L., Baker A., Fuller L., Spötl C., Mattey D., \& McDermott, F., 2006 - Modification and preservation of environmental signals in speleothems. Earth Science Reviews, 75: 105-153. http://dx.doi.org/10.1016/j.earscirev.2005.08.003

Lauritzen S.-E., Ford D.C., \& Schwarcz H.P., 1986 - Humic substances in speleothem matrix - paleoclimatic significance. Proceedings of the $9^{\text {th }}$ International Congress of Speleology, Barcelona, Spain, 2: 77-79.

Perrette Y., 1999 - Les stalagmites: archives environnementales et climatiques à haute resolution. Karstologia, 34, 23-44.

Shopov Y.Y. \& Grynberg M.A., 1985 - A new method for direct photography of luminescence. Expeditional Annual of Sofia University, 1: 139-145.

Shopov Y.Y., 1987 - Laser luminescent microzonal analysis - a new method for investigation of the alterations of the climate and solar activity during Quaternary. In: Kiknadze T. (Ed.), Problems of Karst Study of Mountainous Countries. Meisniereba, Tbilisi: 228-232.

Shopov Y.Y., Dermendjiev V.N., Buyukliev G.I., Georgiev L.N. \& Stoychev T.S., 1988 - Investigations on the variations of the solar activity during the Holocene by means of LLMZA of cave flowstone. Communications of the International Symposium on Physical, Chemical \& Hydrogeological Research of Karst. Kosice, May 10-15, 1988, 97100.

Shopov Y.Y., Ford D.C. \& Schwarcz H.P., 1994 Luminescent microbanding in speleothems: Highresolution chronology and paleoclimate. Geology, 22: 407-410.

http://dx.doi.org/10.1130/0091-7613(1994)022 $<0407$ :LMISHR>2.3.CO;2

Sundqvist H.S., Baker A. \& Holmgren K., 2005 - Luminescence variations in fast-growing stalagmites from Uppsala, Sweden. Geografiska Annaler, 87A: $539-548$.

http://dx.doi.org/10.1111/j.0435-3676.2005.00277.x

Van Beynen P., Bourbonniere R., Ford D. \& Schwarcz H., 2001 - Causes of colour and fluorescence in speleothems. Chemical Geology, 175: 319-341. http://dx.doi.org/10.1016/S0009-2541(00)00343-0 
White W.B. \& Brennan E.S., 1989 - Luminescence of speleothems due to fulvic acid and other activators. Proceedings of the $10^{\text {th }}$ International Congress of Speleology, Budapest, Hungary, 212-214.

White W.B., 1997 - Precise measurement of luminescence banding profiles in speleothems for paleoclimatic interpretation. Proceedings of the $12^{\text {th }}$ International Congress of Speleology, La Chaux de Fonds, Switzerland, 89-92.
White W.B., 2004 - Paleoclimate records from speleothems in limestone caves. In: Sasowsky I.D. \& Mylroie J.E. (Eds.) - Studies of Cave Sediments. Kluwer Academic/Plenum, New York: 135-175. http://dx.doi.org/10.1007/978-1-4020-5766-3_9 